\section{BMJ Open Respiratory Research}

\title{
Patient symptoms and experience following COVID-19: results from a UK-wide survey
}

\author{
Sara Buttery, ${ }^{1}$ Keir E J Philip (D , ${ }^{1}$ Parris Williams, ${ }^{1}$ Andrea Fallas, ${ }^{2}$ Brigitte West, ${ }^{2}$ \\ Andrew Cumella, ${ }^{2}$ Cheryl Cheung, ${ }^{2}$ Samantha Walker, ${ }^{2}$ Jennifer K Quint, ${ }^{3}$ \\ Michael I Polkey, ${ }^{1,4}$ Nicholas S Hopkinson (i) ${ }^{1}$
}

\begin{abstract}
To cite: Buttery S, Philip KEJ, Williams $P$, et al. Patient symptoms and experience following COVID-19: results from a UK-wide survey. BMJ Open Resp Res 2021;8:e001075. doi:10.1136/ bmjresp-2021-001075

- Additional supplemental material is published online only. To view, please visit the journal online (http://dx.doi. org/10.1136/bmjresp-2021001075).
\end{abstract}

Received 10 August 2021 Accepted 19 October 2021

Check for updates

(c) Author(s) (or their employer(s)) 2021. Re-use permitted under CC BY-NC. No commercial re-use. See rights and permissions. Published by BMJ.

${ }^{1}$ National Heart and Lung Institute, Imperial College London, London, UK

${ }^{2}$ Asthma UK and British Lung Foundation Partnership, London, UK

${ }^{3}$ Department of Respiratory Epidemiology, Occupational Medicine and Public Health, Imperial College London, London, UK

${ }^{4}$ Respiratory Medicine, Royal Brompton and Harefield NHS Foundation Trust, London, UK

Correspondence to Dr Nicholas S Hopkinson; n.hopkinson@ic.ac.uk

\section{ABSTRACT}

Objectives To investigate the experience of people who continue to be unwell after acute COVID-19, often referred to as 'Iong COVID', both in terms of their symptoms and their interactions with healthcare.

Design We conducted a mixed-methods analysis of responses to a survey accessed through a UK online postCOVID-19 support and information hub, between April and December 2020, about people's experiences after having acute COVID-19.

Participants 3290 respondents, $78 \%$ female, $92.1 \%$ white ethnicity and median age range $45-54$ years; $12.7 \%$ had been hospitalised. 494(16.5\%) completed the survey between 4 and 8 weeks of the onset of their symptoms, 641(21.4\%) between 8 and 12 weeks and 1865 (62.1\%) $>12$ weeks after.

Results The ongoing symptoms most frequently reported were: breathing problems $(92.1 \%)$, fatigue $(83.3 \%)$, muscle weakness or joint stiffness (50.6\%), sleep disturbances (46.2\%), problems with mental abilities (45.9\%), changes in mood, including anxiety and depression $(43.1 \%)$ and cough (42.3\%). Symptoms did not appear to be related to the severity of the acute illness or to the presence of preexisting medical conditions. Analysis of free-text responses revealed three main themes: (1) experience of living with COVID-19: physical and psychological symptoms that fluctuate unpredictably; (2) interactions with healthcare that were unsatisfactory; (3) implications for the future: their own condition, society and the healthcare system, and the need for research

Conclusion Consideration of patient perspectives and experiences will assist in the planning of services to address problems persisting in people who remain symptomatic after the acute phase of COVID-19.

\section{INTRODUCTION}

The COVID-19 pandemic is one of the most important public health crises of recent history, with substantial impacts on human health and well-being, related both to the direct effects of the condition and the impact of measures to control and reduce infection. ${ }^{1-3}$ Though many people have asymptomatic infection, ${ }^{4}$ others develop COVID-19 disease. Severity of the initial phase varies

\section{Key messages}

What is the experience of having long-term effects of COVID-19 like for people with this condition, particularly in those who were not admitted to hospital during the acute phase of their illness.

- The findings from our study, in a large population, many of whom were not hospitalised during the acute phase of their illness, demonstrate the varying patterns and persistence of symptoms of long COVID, which do not appear to be associated with severity of the acute phase of the disease or preexisting medical conditions. Qualitative findings also enrich the understanding of the patient experience of long COVID symptoms, healthcare interactions and suggestions for future research and service adaptation

- Patient experience should inform the development of services to support people with long COVID and shape follow-up care and management strategies. This will help to address the sense that patients have of being unheard and reassure them that they are being taken seriously, regardless of severity of the acute phase of their initial illness.

dramatically between individuals, from mild flu-like symptoms to multiorgan failure and death. ${ }^{56}$ The pandemic response has largely focused on reducing hospitalisation and mortality from acute COVID- $19^{7}$; however, a substantial proportion of people experience long-term symptoms. ${ }^{8-14}$

As a relatively new and complex phenomenon, the syndromes and terminology involving persisting symptoms following acute COVID-19 are inconsistently defined..$^{15}$ A recent National Institute for Health and Care Excellence (NICE) clinical guideline for the management of people with symptoms following COVID-19 subcategorises this into 'ongoing symptomatic COVID-19' for people with persistent symptoms 4-12 weeks after the start of acute COVID-19 and 'post-COVID-19 syndrome' for those whose 
symptoms have not resolved 12 weeks after the onset of acute COVID-19. ${ }^{16}$ Persisting symptoms are likely to be underpinned by a range of processes that are yet to be fully established, including organ damage, cognitive processing disorders, autonomic dysfunction and continuing inflammatory response and/or blood clotting disorders. ${ }^{15}$ In this paper, we use the term 'long COVID', which appears popular among people experiencing prolonged symptoms, with some also adopting the phrase 'long-haulers'. ${ }^{\text {16-18 }}$

We analysed responses to an online survey of people with long COVID to explore symptom frequency, patient experience and identify key themes to improve understanding of the condition and inform healthcare responses.

\section{METHODS}

We used a mixed methods approach, combining quantitative and qualitative methods, to analyse data from a UK wide survey conducted in April 2020, via an online PostCOVID hub https://wwwpost-covidorguk/. The survey asked respondents about the presence and duration of symptoms, the level of treatment they had required during their initial COVID-19 illness (eg, at home or in hospital) and their experience of care, support and information received during and after this.

Thematic analysis of free-text responses to the questions 'How would you describe your experience after COVID19 ?' and 'Please describe what kind of follow-up support you would ideally like to receive from your healthcare providers' was undertaken by SB, PW and KEJP based on the approach described by Braun and Clarke. ${ }^{19}$ Additional details of the survey and thematic analysis are available in online supplemental file 2.

Statistical analyses were performed using SPSS V.27. Demographic data and information about pre-existing health conditions were collated and presented by groups according to the level of treatment received during the initial phase of the illness (community vs hospitalised). Statistical testing was also carried out to investigate any differences in symptoms between those reporting preexisting health conditions (ie, breathing problems in those with respiratory disease or mood disorders in those with existing mental health diagnoses), compared with those who did not. Between-group differences were compared using $\chi^{2}$ test or independent t-tests as appropriate, with $\mathrm{p}<0.05$ taken to indicate statistical significance. Where there were ordinal variables (eg, age groups) a midpoint of each category was taken to allow statistical testing to be performed. For categories with very small numbers, adjacent categories were collapsed together to allow for comparison. In the case of duplicate entries, the most recent was used for analysis.

Participants were required to give informed consent for the use of their data for this purpose at the start of the survey.
Patient and public involvement

Patients and members of the public were not specifically involved in the design, conduct or reporting of this research, and study participant validation of the themes was not possible due to the nature of data collection methods used; however, the findings were discussed with, and reviewed by, expert patients with long COVID.

\section{RESULTS}

There were 3648 responses between 28 April 2020 and 15 December 2020 which, excluding 273 blank entries and 85 duplicates, left a final sample of 3290 for analysis (table 1). Seventy-eight per cent of respondents were female, $92.1 \%$ reported white ethnicity and the most frequently represented age range was $45-54$ years. A total of $2873(87.3 \%)$ had remained at home during their acute illness and $417(12.7 \%)$ had been admitted to hospital for treatment. The prevalence of asthma in our cohort was high $(26.3 \%)$ in comparison with other preexisting conditions.

The most frequently reported symptoms were breathing problems $(92.1 \%)$, fatigue $(83.3 \%)$, muscle weakness or joint stiffness $(50.6 \%)$, sleep disturbances $(46.2 \%)$, problems with mental abilities (45.9\%), changes in mood, including anxiety and depression (43.1\%) and cough $(42.3 \%)$. There was no statistical difference in symptom pattern between those who had been hospitalised and the rest of the survey population (figure 1/online supplemental table E1).

Respondents most frequently reported five to seven coexisting symptoms $(40.1 \%)$ with a mean (SD) of 5.0 (2.3) (figure 2). People with pre-existing lung disease $(27.6 \%)$ were more likely to report post-COVID-19 breathing problems compared with those without, although the difference was numerically small $(88.4 \%$ vs $\left.83.7 \% ; \chi^{2} 11.6, \mathrm{p}=0.001\right)$. Changes in mood were commonly reported; however, there was no significant difference between those with or without pre-existing anxiety and/or depression ( $24.7 \%$ vs $22.4 \%)\left(\chi^{2} 1.262\right.$, $\mathrm{p}=0.261)$.

Two hundred and seventy respondents (8.2\%) completed the survey $<4$ weeks after the onset of symptoms, 494 respondents $(15.0 \%)$ between 4 and 8 weeks of the onset of their symptoms, $642(19.5 \%)$ between 8 and 12 weeks and $1865(56.7 \%)$ completed the survey after 12 weeks of symptom onset. The demographics of people completing the survey at different time points were similar, with a tendency for increase in age as duration of symptoms increased (table 2). There were some differences in the pattern of symptoms. Breathing problems and extreme tiredness or fatigue did not vary, but changes in mood, extreme tiredness or fatigue, hair loss, muscle weakness or joint stiffness, problems with mental abilities, sleep problems and symptoms of posttraumatic stress disorder were all more prevalent in those reporting after a longer interval. By contrast, symptoms of cough and loss of taste or smell were more prevalent in 
Table 1 Demographics of all survey participants and $(A)$ those who were not hospitalised and $(B)$ those who were hospitalised

\begin{tabular}{|c|c|c|c|c|}
\hline & All, $n=3290$ & $\begin{array}{l}\text { Not hospitalised, } \\
n=2873\end{array}$ & $\begin{array}{l}\text { Hospitalised, } \\
n=417\end{array}$ & $P$ value \\
\hline \multicolumn{5}{|l|}{ Gender } \\
\hline Female & $2565(78.0)$ & $2269(79.0)$ & $296(71.0)$ & $<0.001$ \\
\hline Male & $686(20.9)$ & $568(19.8)$ & $118(28.3)$ & \\
\hline \multicolumn{5}{|l|}{ Age (years) } \\
\hline 17 or under & $6(0.2)$ & $4(0.1)$ & $2(0.5)$ & \\
\hline $18-24$ & $55(1.7)$ & $51(1.8)$ & $4(1.0)$ & \\
\hline $24-34$ & $407(12.4)$ & $373(13.0)$ & $34(8.2)$ & \\
\hline $35-44$ & $778(23.6)$ & $702(24.4)$ & $76(18.2)$ & $<0.001$ \\
\hline $45-54$ & $1117(34.0)$ & $988(34.4)$ & $129(31.0)$ & \\
\hline $55-64$ & $693(21.1)$ & $571(19.9)$ & $122(29.3)$ & \\
\hline $65-74$ & $193(5.9)$ & $153(5.3)$ & $40(9.6)$ & \\
\hline 75 or older & $40(1.2)$ & $30(1.0)$ & $10(2.4)$ & \\
\hline \multicolumn{5}{|l|}{ Ethnicity } \\
\hline White & $3031(92.1)$ & $2684(93.4)$ & $379(91.0)$ & \\
\hline Black, African, black British or Caribbean & $41(1.2)$ & $31(1.1)$ & $10(2.4)$ & 0.07 \\
\hline Asian or Asian British & $91(2.8)$ & $77(2.7)$ & $15(3.6)$ & \\
\hline Mixed or multiple ethnic groups & $56(1.7)$ & $49(1.7)$ & $7(1.7)$ & \\
\hline \multicolumn{5}{|l|}{ Nation } \\
\hline England & $2742(83.3)$ & 2408 (83.8) & $330(79.1)$ & \\
\hline Scotland & $271(8.2)$ & $226(7.9)$ & $43(10.3)$ & 0.609 \\
\hline Wales & $155(4.7)$ & $134(4.7)$ & $21(5.0)$ & \\
\hline Northern Ireland & $43(1.3)$ & $30(1.0)$ & $13(3.1)$ & \\
\hline \multicolumn{5}{|l|}{ Current work status } \\
\hline Working full time & $1104(33.6)$ & $989(34.4)$ & $111(26.6)$ & \\
\hline Working part time & $532(16.2)$ & $483(16.8)$ & $50(12.0)$ & \\
\hline Student & $48(1.5)$ & $40(1.4)$ & $8(1.9)$ & 0.003 \\
\hline Retired & $304(9.2)$ & $242(8.4)$ & $63(15.1)$ & \\
\hline Not working because of COVID-19 & $889(27.0)$ & $744(25.9)$ & $138(33.1)$ & \\
\hline Not working for other reasons & $267(8.1)$ & $238(8.3)$ & $31(7.4)$ & \\
\hline \multicolumn{5}{|l|}{ Total household income } \\
\hline Below $£ 20000$ & $550(16.7)$ & $458(15.9)$ & $93(22.3)$ & \\
\hline$£ 20000-£ 30000$ & $556(16.9)$ & $487(17.0)$ & $69(16.5)$ & \\
\hline$£ 30001-£ 40000$ & $510(15.5)$ & $341(11.9)$ & 65 (15.6) & $<0.001$ \\
\hline$£ 40001-£ 70000$ & $796(24.2)$ & $700(24.4)$ & $95(22.8)$ & \\
\hline Over $£ 70000$ & $496(15.1)$ & $448(15.6)$ & $45(10.8)$ & \\
\hline \multicolumn{5}{|l|}{ Pre-existing health condition } \\
\hline Anxiety & $390(11.9)$ & $335(11.7)$ & 55 (13.2) & 0.37 \\
\hline Asthma & $866(26.3)$ & $723(25.2)$ & $143(34.3)$ & $<0.001$ \\
\hline Bronchiectasis & $32(1.0)$ & $22(0.8)$ & $10(2.4)$ & $<0.001$ \\
\hline Cancer & $32(1.0)$ & $28(1.0)$ & $4(1.0)$ & 0.98 \\
\hline CVD & $58(1.8)$ & $42(1.5)$ & $16(3.8)$ & 0.001 \\
\hline CKD & $16(0.5)$ & $11(0.4)$ & $5(1.2)$ & 0.025 \\
\hline COPD & $58(1.6)$ & $43(1.5)$ & $14(3.4)$ & 0.01 \\
\hline
\end{tabular}




\begin{tabular}{lcccc}
\hline Table 1 Continued & & & & \\
\hline & All, $\mathbf{n = 3 2 9 0}$ & $\begin{array}{l}\text { Not hospitalised, } \\
\mathbf{n = 2 8 7 3}\end{array}$ & $\begin{array}{l}\text { Hospitalised, } \\
\mathbf{n = 4 1 7}\end{array}$ & P value \\
\hline Depression & $287(8.7)$ & $240(8.4)$ & $47(11.3)$ & 0.05 \\
Diabetes & $71(2.2)$ & $50(1.7)$ & $21(5.0)$ & $<0.001$ \\
HTN & $255(7.8)$ & $202(7.0)$ & $53(12.7)$ & $<0.001$ \\
ILD & $2(0.1)$ & $2(0.1)$ & $0(0.0)$ & 0.59 \\
Obesity & $218(6.6)$ & $173(6.0)$ & $45(10.8)$ & $<0.001$ \\
\hline
\end{tabular}

Data are presented as $\mathrm{n}(\%)$. Statistical tests compare hospitalised and not hospitalised groups. $\mathrm{P}$ values are for $\chi^{2}$ or $\mathrm{t}$ test as appropriate. Where numbers do not total $100 \%$, missing values are due to questions unanswered by participants.

CKD, chronic kidney disease; COPD, chronic pulmonary disease; CVD, cardiovascular disease; HTN, hypertension; ILD, interstitial lung disease.

the earlier stages after the acute illness. More coexisting symptoms were reported in those reporting longer after their initial illness.

In the 417 respondents who reported being hospitalised with COVID-19, $57.1 \%$ were in hospital for less than 1 week, while $17 \%$ were in for more than 2 weeks (online supplemental table E2). As expected, pre-existing medical conditions were more prevalent in people who had required hospital care. Among hospitalised patients, $33.6 \%$ reported not needing any sort of respiratory support during the acute phase of their illness, 50.4\% required non-invasive support with their breathing (eg, supplemental oxygen, and continuous positive airways pressure (CPAP)) and 10.6\% had required endotracheal intubation. Those who had required intubation were no more likely to report ongoing breathing difficulties than those who had not $(86.4 \%$ vs $92.6 \% ; \mathrm{p}=0.485)$. Of note, only $7 \%$ reported receiving a rehabilitation plan on discharge from hospital.

$27.4 \%$ of all respondents reported that they had not spoken to their general practitioner (GP) or nurse, and only $27.9 \%$ reported being given information about things that they could do to aid their recovery. The quality of communication and information received (scored on

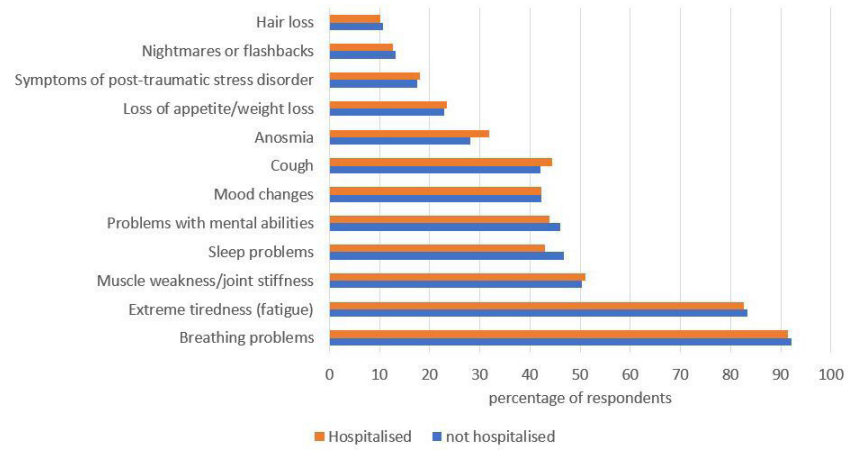

Figure 1 Frequency of symptoms reported by postCOVID-19 survey respondents graph showing percentages of individuals with long COVID reporting each symptom. Orange bar: people hospitalised during their acute COVID-19 illness ( $n=417)$; blue bar; not hospitalised $(n=2873)$. a scale of $0-10$ ) was rated more highly in the hospitalised group in terms of clarity, usefulness, timeliness and empathy compared with those who had remained at home (online supplemental table E2).

In terms of importance (rated out 0-10), advice from healthcare professionals on managing difficulties after COVID-19 scored highest numerically (9.0); general information on difficulties after COVID-19 (8.9); the latest medical research on difficulties after COVID-19 (8.9); and reading about and talking to other people who have difficulties after COVID-19 (8.4) were all rated highly (online supplemental file 2 ).

\section{Thematic analysis}

Three key themes were identified from survey responses: (1) experience of living with COVID-19 - physical and psychological symptoms that fluctuate unpredictably; (2) interactions with healthcare; and (3) implications for the future - their own condition, society and the healthcare system and the need for research (figure 3 ). The characteristics of individuals quoted are given in online supplemental file 2 .

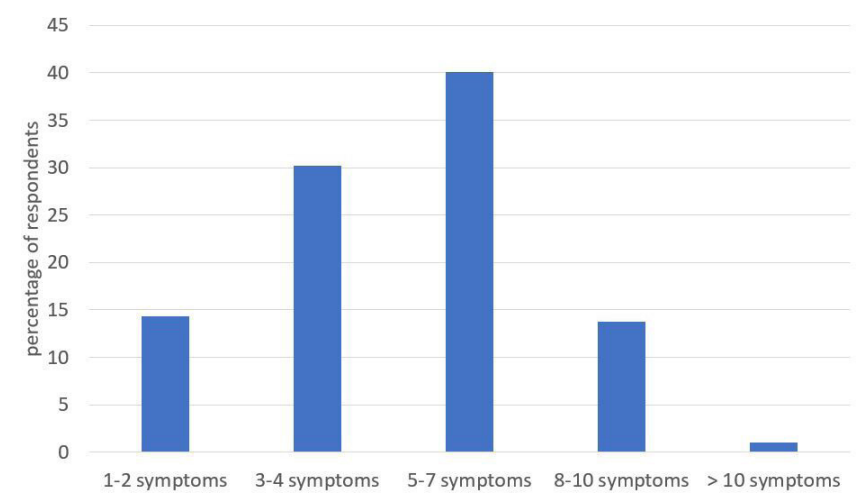

Figure 2 Number of symptoms reported by postCOVID-19 survey respondents. Respondents reported a mean (SD) of 5.0 (2.3) symptoms. 
Table 2 Symptoms reported in those who report: (A) <4 weeks since symptom onset; (B) 4-8 weeks since symptoms onset; (C) 8-12 weeks since symptoms onset; (D) $>12$ weeks since symptoms onset

\begin{tabular}{|c|c|c|c|c|c|}
\hline & $\begin{array}{l}<4 \text { weeks, } \\
\mathrm{n}=270\end{array}$ & $\begin{array}{l}\text { 4-8weeks, } \\
\mathrm{n}=494\end{array}$ & $\begin{array}{l}\text { 8-12 weeks, } \\
\mathrm{n}=641\end{array}$ & $\begin{array}{l}>12 \text { weeks, } \\
\mathrm{n}=1865\end{array}$ & $P$ value \\
\hline \multicolumn{6}{|l|}{ Gender } \\
\hline Female & $214(79.3)$ & $387(78.3)$ & $506(78.9)$ & $1440(77.2)$ & 0.714 \\
\hline Male & $52(19.3)$ & $98(19.8)$ & $131(20.4)$ & $403(21.6)$ & \\
\hline \multicolumn{6}{|l|}{ Age (years) } \\
\hline 17 or under & $0(0.0)$ & $1(0.2)$ & $1(0.2)$ & $4(0.2)$ & \\
\hline $18-24$ & $9(3.3)$ & $8(1.6)$ & $8(1.2)$ & $30(1.6)$ & \\
\hline $24-34$ & $40(14.8)$ & 65 (13.2) & $82(12.8)$ & $220(11.8)$ & \\
\hline $35-44$ & $64(23.7)$ & $123(24.9)$ & $159(24.8)$ & $427(22.9)$ & 0.038 \\
\hline $45-54$ & $91(33.7)$ & $168(34.0)$ & $222(34.6)$ & $630(33.8)$ & \\
\hline $55-64$ & $51(18.9)$ & $96(19.4)$ & $137(21.4)$ & $402(21.6)$ & \\
\hline $65-74$ & $13(4.8)$ & $22(4.5)$ & $28(4.4)$ & $128(6.9)$ & \\
\hline 75 or older & $2(0.7)$ & $10(2.0)$ & $4(0.6)$ & $24(1.3)$ & \\
\hline \multicolumn{6}{|l|}{ Ethnicity } \\
\hline White & $242(89.6)$ & $457(92.5)$ & $609(95.0)$ & $1735(93.0)$ & \\
\hline Black, African, black British or Caribbean & $5(1.9)$ & $7(1.4)$ & $6(0.9)$ & $23(1.2)$ & \\
\hline Asian or Asian British & $15(5.6)$ & $17(3.4)$ & $12(1.9)$ & $48(2.6)$ & 0.089 \\
\hline Mixed or multiple ethnic groups & $3(1.1)$ & $7(1.4)$ & $10(1.6)$ & $36(1.9)$ & \\
\hline \multicolumn{6}{|l|}{ Symptoms } \\
\hline Breathing problems & $246(91.1)$ & $460(93.1)$ & $596(93.0)$ & 1707 (91.5]) & 0.47 \\
\hline Changes in mood, or anxiety or depression & $93(34.4)$ & $206(41.7)$ & $266(41.5)$ & $842(45.1)$ & 0.006 \\
\hline Cough & $135(50.0)$ & $221(44.7)$ & $275(42.9)$ & $752(40.3)$ & 0.013 \\
\hline Extreme tiredness/fatigue/lack of energy & $216(80.0)$ & $406(82.2)$ & $535(83.5)$ & $1568(84.1)$ & 0.338 \\
\hline Hair loss & $10(3.7)$ & $24(4.9)$ & $61(9.5)$ & $248(13.3)$ & $<0.001$ \\
\hline Loss of appetite or weight loss & $70(25.9)$ & $126(25.5)$ & $126(19.7)$ & $430(23.1)$ & 0.069 \\
\hline Loss of taste or smell (anosmia) & $120(44.4)$ & $152(30.8)$ & $172(26.8)$ & $488(26.2)$ & $<0.001$ \\
\hline Muscle weakness or joint stiffness & $118(43.7)$ & $235(47.6)$ & $315(49.1)$ & $984(52.8)$ & 0.012 \\
\hline Nightmares or flashbacks & $25(9.3)$ & $60(12.1)$ & $69(10.8)$ & $273(14.6)$ & 0.012 \\
\hline $\begin{array}{l}\text { Problems with mental abilities including } \\
\text { anxiety/depression }\end{array}$ & $79(29.3)$ & $192(38.9)$ & $279(43.5)$ & $950(50.9)$ & $<0.001$ \\
\hline Sleep problems & $112(41.5)$ & $233(47.2)$ & $296(46.2)$ & $887(47.6)$ & 0.196 \\
\hline Symptoms of PTSD & $35(13.0)$ & $74(15.0)$ & $111(17.3)$ & $352(18.9)$ & 0.037 \\
\hline Number of coexisting symptoms & $4.7 \pm 2.1$ & $4.8 \pm 2.3$ & $4.8 \pm 2.3$ & $5.1 \pm 2.4$ & 0.005 \\
\hline \multicolumn{6}{|l|}{ Treatment during acute phase of virus } \\
\hline Self-treatment at home & $229(84.8)$ & $404(81.8)$ & $575(89.7)$ & $1652(88.6)$ & $<0.001$ \\
\hline Hospitalised (but not intensive care) & $32(11.9)$ & $68(13.8)$ & $52(8.1)$ & $160(8.6)$ & \\
\hline Hospitalised (intensive care) & $9(3.3)$ & $22(4.5)$ & $14(2.2)$ & $53(2.8)$ & \\
\hline
\end{tabular}

Data are presented as $n(\%)$ or mean (SD). P values of $<0.05$ are for $\chi^{2}$ or one-way analysis of variance as appropriate. Where numbers do not total $100 \%$, missing values are due to questions unanswered by participant. Changes of mood are taken to indicate a negative change in mood (ie, more anxious, more depressed, etc).

PTSD, post-traumatic stress disorder.

Experience of living with COVID-19

Typically, respondents described multiple, often disabling symptoms causing major disruption to daily life and functioning. Both physical and psychological symptoms were common, frequently overlapping and often exacerbated one another. Frustratingly for many, the ongoing disease course was non-linear, with recurrent and unpredictable symptomatic relapses. Participants highlighted the need to understand the long-lasting consequences of COVID19 , not just the immediate risk of death. Many individuals 


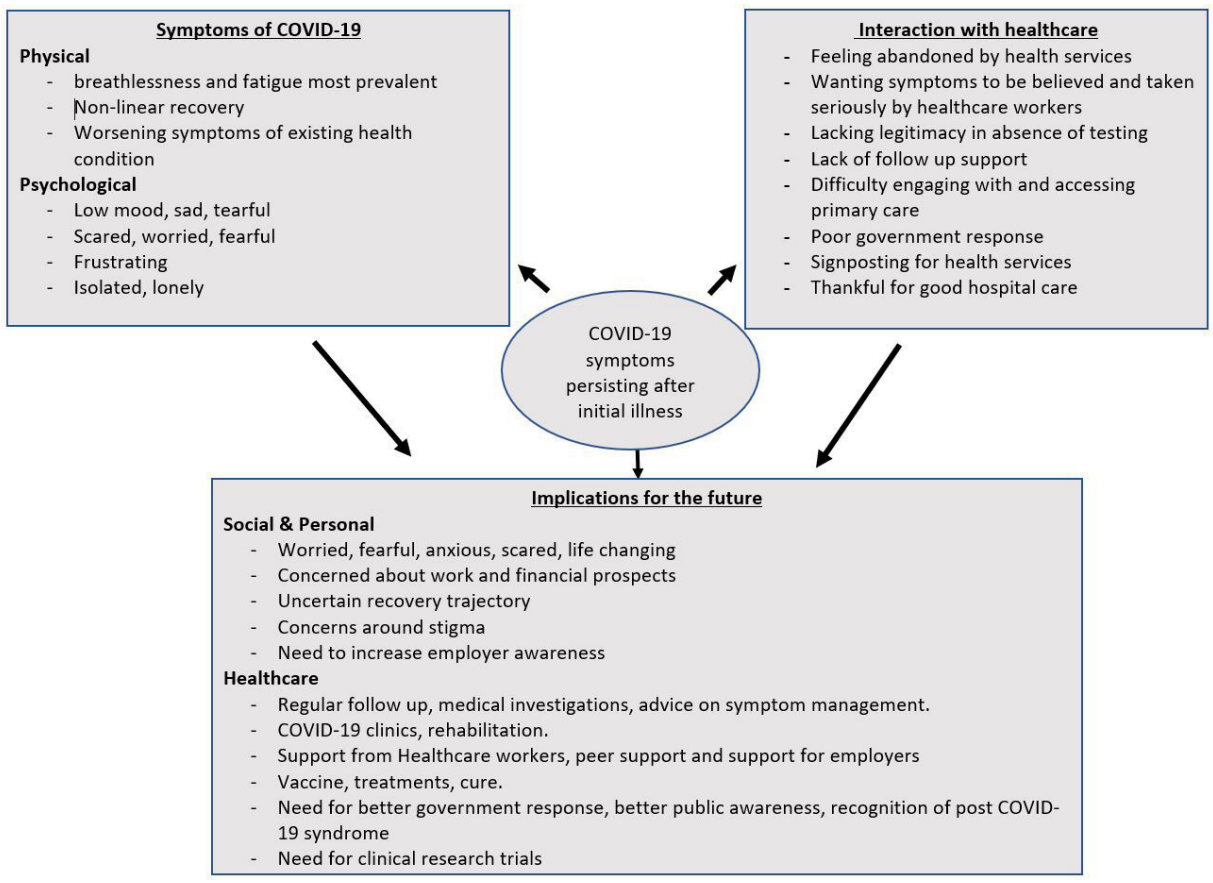

Figure 3 Thematic analysis of long COVID experience.

reported continuing to suffer with a range of physical symptoms, the most common being breathlessness and fatigue, which mirrors our quantitative findings.

Breathing is difficult on minor exertion, unable to walk upstairs without becoming short of breath, moderate exertion (walking up 4 or 5 floors) leads to a period of extreme breathlessness and exhaustion, unable to walk further.

Constant fatigue is a real problem.

Returning to normal life was almost impossible for some. Often even basic daily activities were limited, in people who prior to getting ill had seen themselves as healthy (figure 4).

I just feel tired weak and sore all over. I lack the same energy I had to go about my daily life.

I tested positive over 4 weeks ago, normally fit and healthy, now I get breathlessness really quickly. Even just walking around the house, or washing the dishes, triggers it.

Many described their disease course as cyclical, with fluctuating symptoms and 'false recoveries' (figure 4).

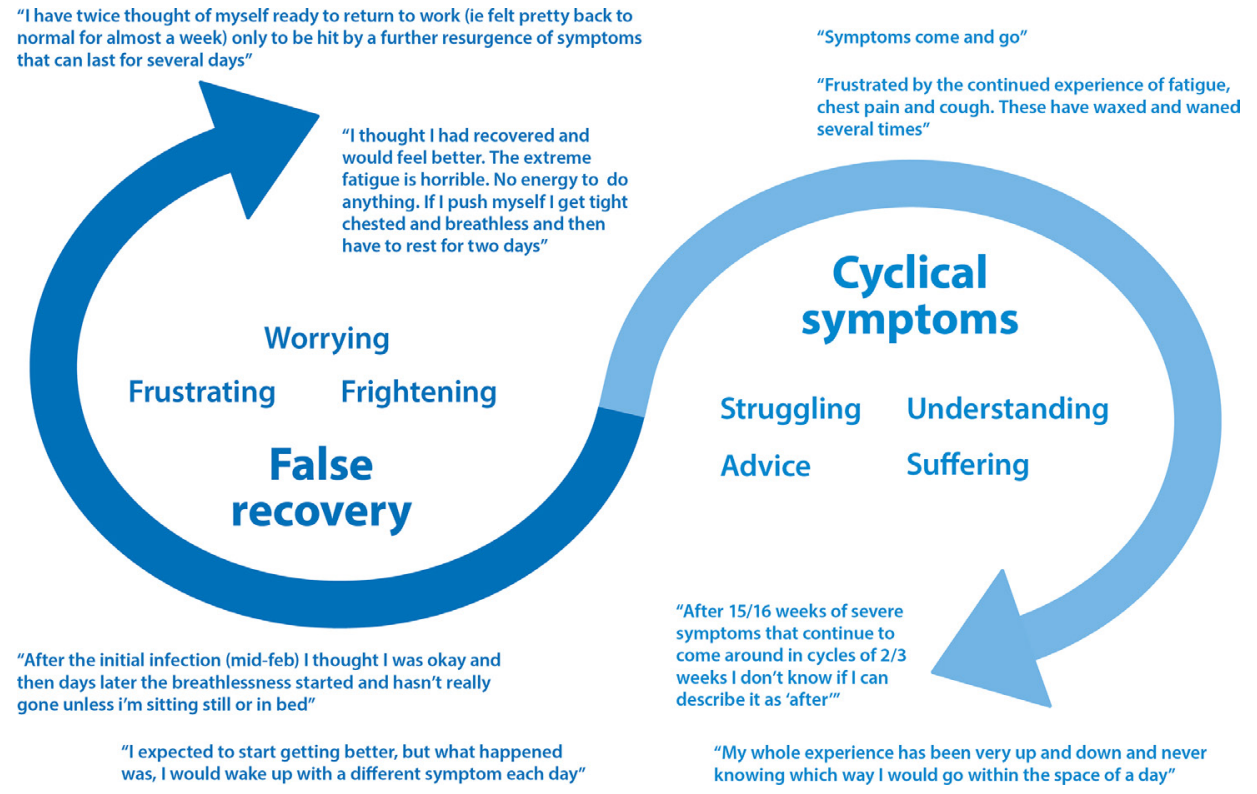

Figure 4 Infographic demonstrating the recovery/cyclical nature of long COVID symptoms from the respondent perspective. 
I feel like I'm on the mend and then have a massive set back. It is very depressing. I was doing better for the last 6 weeks, then recently had a relapse where my breathlessness is back, and my fatigue is back. Very frustrating! One step forward and three steps back.

Uncertainty regarding the duration of symptoms, and completeness of recovery, was a major source of distress and was compounded by the general lack, and ambiguity, of information from healthcare providers regarding their condition (figure 4).

Understanding what is causing breathing difficulties, for example, scarring or inflammation, and evidence on how long these symptoms are likely to last. And evidence that a full recovery is likely.

Psychological problems were pronounced with around half $(43.1 \%)$ reporting persistent and debilitating anxiety. Psychological distress had multiple origins, including physical symptoms, relapsing disease course and barriers to care.

I have noticed my anxiety has increased a lot. I know it's post-COVID symptoms but sometimes I doubt myself and think there is something else? it's very worrying however; I can manage my symptoms but it's more anxiety that creates more issues!

'Scared' and 'fearful' were repeatedly used to describe emotional status both in terms of respondents' current position and their expectations for the future. Others described feeling lonely or isolated and low mood was common.

Frightening, confusing, lonely, lacking support, worried to tell people in case they don't believe me or think I'm infectious, frustrating... it's hard sometimes not to feel bleak due to not knowing what the long term implications are, what will happen if I get it again, are any [of] my organs damaged and going to fail in the future.

\section{Interactions with healthcare}

Among comments about accessing care, perceptions and experiences were largely dichotomised between those who felt well supported and those who did not. Thus, many participants described feeling let down or abandoned by healthcare services, consistent with almost a third $(27.4 \%)$ having not spoken to a GP or nurse about their difficulties.

I feel very deserted and alone by health care professionals.

Many participants described themselves as the forgotten patients of COVID-19. This cohort had experienced mild to severe symptoms but remained at home and were unable to be tested due to the lack of available tests.
Frustrating! No access to tests, swab and antibody, 'til way too late, resulting in negative outcome. GP's refusing to refer me to specialists, insisting I was 'fine' when clearly not - unable to breathe/speak. Only got referral by keep pushing GP, very tiring... Went to local A\&E by ambulance in late June, as severe breathing problems and chest pain, 111 thought I might be having heart attack. Docs v dismissive and felt I was wasting their time. Charming!

Experiences with the NHS 111 helpline and interacting with their GP could be negative; many felt that their primary care providers did not believe that they had long COVID symptoms and suggested their symptoms were due to stress/anxiety.

At the height of the illness in mid-March I fully expected to die. There was zero medical help, I was told to lock myself in my room and cope the best I can while struggling to breathe or move. My GP referred all COVID calls to NHS111, NHS111 took hours and if I hadn't got through to a knowing doctor by the time I was coughing up blood, who prescribed me strong antibiotics, if COVID hadn't got me, pneumonia would have done.

The feeling that their healthcare providers did not believe them or dismissed symptoms as being due to anxiety was frustrating.

[we need] Follow up for prolonged symptoms and clear self-help guidelines. To not be told it is anxiety and made to feel like it's not real.

Not feeling believed by healthcare professionals was a strong theme throughout, and participants felt their symptoms were being unfairly questioned. One individual described his experience as being 'gaslighted' by his GP.

It has been an awful time and it made it worse, when I felt that I wasn't being believed about the symptoms. I didn't think I'd still be ill 8 months later. I feel there is very little support and my GP has ignored my symptoms. He has put it down to anxiety disorder. Which is so unfair. I know my body, and never have I experienced a burning sensation in my chest and breathing problems before.

By contrast, the respondents who reported feeling well supported were largely those who had been admitted to hospital and had laboratory confirmation of COVID-19 in the acute stages of their illness. This was even more marked for those who had been admitted to an HDU/ ICU, who described the care and support they received in a very positive light.

I've been quite happy with the treatment I've received in my local hospital it's been reassuring Breathing Space keeping in touch. 


\section{Implications for the future}

A third theme centred on individuals' future prospects and uncertainty regarding their symptoms, disease course and hopes for recovery to normal work and social life; future societal and healthcare professional understanding of their illness and structures of care, and the need for research and better treatments. Participants described their experience with COVID-19 as 'life-changing' with implications for many aspects of their life. The ongoing daily battle or 'fight' was repeatedly described as exhausting, with individuals despairing about their prospects in the future. Responses frequently addressed concerns related to their symptoms and employment situation. Many had not been able to return to their full duties at work, while others had not been able to return to work at all.

Can't go back to work as I still feel so unwell and my work (I am a teacher) are trying to push me into going back as I'm out of the 14-day infectious period and they are short staffed.

This caused significant financial stress, especially in the absence of a firm diagnosis to allow them to be signed off work or any certainty as to when things may get better. Increased need for extra help and care since contracting the virus was common. For many, this came from family members causing extra stress on loved ones and their relationships. For those requiring paid external care, the lack of funding available for this was noted.

I feel there is not much help for survivors in terms of emotional and financial support. One is left to figure out how best to manage on their own... because you do not have the financial support especially as a single parent you have to force and drag yourself to work in order to pay bills. Instead of concentrating on the healing process you are left with no choice but to work.

Participants expressed their hopes for the future in terms of increasing knowledge and awareness as well as access to further support interventions. This was needed especially for those who had not been admitted to hospital but were still experiencing longer lasting symptoms of the virus. In this context, more medical investigations including chest X-rays, blood test analysis and antibody testing were requested to identify and confirm disease status.

I would really like a thorough examination, (chest $\mathrm{x}$-ray for example) to determine precisely what the problems are and how best they can be resolved.

More access to medical checks for reassurance and an antibody test as my case was unconfirmed due to lack of testing at the time.

Others considered the availability of long COVID clinics to be of great value in providing ongoing support, advice and treatment for recovery from the virus.
Clinics set up with multi-disciplinary teams to address all aspects of recovery would be the best way forward for us all.

As well as a desire for recovery and return to "normal life', there was also a need for more practical advice of how persistent symptoms could be managed. Suggestions such as increased rehabilitation services, breathing control exercises and energy conservation or pacing strategies were frequently mentioned, implying participants were anticipating or had experienced a very slow or incomplete recovery.

A programme of exercises starting from very simple movements and building up to more strenuous that can be used to rebuild strength \& stamina gradually as fatigue \& general malaise allow, taking into consideration the frequent relapses I have experienced every time I begin to improve a little! More information on how to cope with breathlessness. Techniques of breathing to help symptoms.

Hopes for future research into the longer term effects of COVID-19 were repeatedly mentioned in relation to vaccination, new treatments and a cure but also more generally to increase the knowledge base and understanding of the public, National Health Service (NHS) and government.

That there is government advice for people with long COVID. Recognition, guidance and support is not there.

There needs to be more information and research looking into individuals experiencing pro longed mild/moderate (ie, more than 4 weeks) symptoms during recovery for COVID.

\section{DISCUSSION}

People living with long COVID experience multiple, varying physical and psychological symptoms that are not necessarily related to initial illness severity or pre-existing health conditions. Interactions with healthcare are often unsatisfactory in terms of both the treatment that is available and the perceived legitimacy of their condition. This is accompanied by uncertainty about the future. Barriers to accessing healthcare and follow-up support exist and are experienced especially by people who managed the acute phase of their illness at home and did not have laboratory confirmation of COVID-19. This is the first study to investigate both symptoms and patient experience post-COVID-19, in a large cohort using both quantitative and qualitative methods.

\section{Significance of findings}

Long COVID is thought to affect approximately $10 \%$ of people who develop COVID-19, ${ }^{16}$ although estimates vary widely. ${ }^{20}{ }^{21}$ Our findings demonstrate the varying patterns and persistence of symptoms of long COVID, which do not necessarily appear to be associated with severity of 
the acute phase of the virus and are in keeping with those presented by other recent papers. ${ }^{8-13}$ The most common symptoms reported in this study of people with long COVID were breathing problems and fatigue. A European study of 2113 people recruited online, also found that fatigue and dyspnoea were the most prevalent symptoms postacute COVID-19 with a median of six symptoms per person persisting. ${ }^{22}$ We found that rates of reporting post-COVID-19 breathing problems differed by only a small amount between those who did or did not have pre-existing lung disease, consistent with a previous small study. ${ }^{13}$ Interestingly, the Zoe COVID-19 Symptom Study has identified asthma as the only pre-existing long-term condition associated with an increased risk of developing long COVID.

The variation in symptoms described supports the concept of long COVID comprising multiple different, often overlapping and coexisting syndromes. ${ }^{15}$ Having taken a mixed methods approach, our findings illustrate people's symptoms and how these impact on their lives, an understanding of which is vital in guideline and service development. ${ }^{23}$ The themes that emerged from analysis of responses to this survey support those from a study, using interviews and focus groups to study lived experiences of long COVID in 114 participants, ${ }^{24}$ which identified comparable themes including access to healthcare services, concepts of improvements for the future and supported the need to establish quality principles for a long COVID service. Our work strengthens these findings, building the evidence base around the lived experience of long COVID in a larger cohort.

Many of our respondents reported difficulties when interacting with primary care services regarding their symptoms. Funding for long COVID services from NHS England was launched in November 2020. ${ }^{25}$ However, access to these services requires referral from a general practitioner (GP), and participant responses highlight that a greater understanding of how long COVID can be recognised and distinguished from other possible causes of symptoms is needed. It is worth noting that provision of rehabilitation services was already inadequate prior to the pandemic. ${ }^{26}$ Acknowledging the legitimacy of patient symptoms and diagnosis, especially in the absence of testing at the time of their initial illness, is important. NICE recently published best practice guidance on identifying and assessing those with symptoms post-COVID-19 and recommendations for management and follow-up. ${ }^{17}$ Further research efforts and initiatives are responding to the impact on individuals' lives caused by the pandemic ${ }^{27}$ including an online portal established by the NHS for people with long-term symptoms (https://www. yourcovidrecovery.nhs.uk/). ${ }^{28}$ Patient experience must be included in planning long COVID care, including the development of public understanding and perception, appropriate healthcare management strategies and research prioritisation. ${ }^{29}$ Potential delivery of such services includes the use of novel virtual models ${ }^{30-32}$ and their role in supporting physical and cognitive recovery, ${ }^{33}$ using multidisciplinary input to tackle a multitude of needs has been evaluated. ${ }^{33}$ The HEAL-COVID study (https://clinicaltrials.gov/ct2/show/NCT04801940) also aims to identify and evaluate treatments that may be beneficial for people recovering from COVID-19. However, these studies focus only on patients who have been admitted to hospital, and thus far, similar studies have not been conducted in those patients who remained at home, but continue to experience ongoing symptoms.

\section{Methodological issues}

This is one of the largest studies to date exploring the lived experience of people with long COVID, and the inclusion of a large number of people who managed their acute illness at home provides important insight into this largely unseen group. Some limitations should be noted. The survey was completed by people who considered themselves to have long COVID and had chosen to visit an online site about the condition. As such, it contains important information about patient experience, but as a self-selecting population, the data cannot be used to make inferences about the experience or epidemiology of everyone who develops COVID-19. Furthermore, none of the reported symptoms or pre-existing health conditions were validated with an outcome measure or confirmed diagnosis, but rather were based only on subjective questioning.

Although a large sample, it is unclear how representative it is of all people with long COVID, as our sample has high proportions of women and white people. However, emerging research suggests that females may be at an increased risk of developing long COVID ${ }^{15}$ Although the prevalence of asthma was $26 \%$ in our cohort, this was similar to that seen in the ISARIC dataset: $21 \%$ for 16-49 year olds. ${ }^{34}$ A degree of sampling bias towards those with higher levels of digital literacy and individuals with more severe ongoing symptoms may have occurred, as such individuals could plausibly be more likely to be seeking online sources of support such as through the post-COVID-19 hub.

\section{CONCLUSION}

The three themes we identified each require specific attention to improve the understanding and management of long COVID. (1) Symptoms: how to relieve and better understand them; (2) healthcare: how to make it accessible for all people experiencing persisting effects of COVID-19, not just those admitted to hospital, and in particular those who did not have a COVID-19 test at the time of their initial illness; (3) uncertainty: reducing this by communicating existing knowledge more effectively and undertaking research to improve understanding of mechanisms and prognosis.

The COVID-19 pandemic reaches far beyond the acute phase of the illness. People with long COVID have substantial unmet care needs, and although services are being developed to address these needs, many people 
experience prohibitive barriers, including feeling that their condition is not being taken seriously by healthcare providers.

Contributors SB and KEJP carried out the quantitative analysis. SB, KEJP and PW conducted the thematic analysis. SB wrote the first draft to which all authors contributed. The survey was developed by AUK-BLF partnership (AF, AC, SW and BW). All authors have reviewed and approved the final version. The corresponding author attests that all listed authors meet authorship criteria and that no others meeting the criteria have been omitted. NSH is the guarantor.

Funding KEJP was supported by the Imperial College Clinician Investigator Scholarship. KP would like to acknowledge the National Institute for Health Research Biomedical Research Centre based at Imperial College Healthcare National Health Service Trust and Imperial College London for their support.

Competing interests None declared.

Patient consent for publication Consent obtained directly from patient(s)

Ethics approval Ethical approval was granted by the Imperial College Research Governance and Integrity Team (ICREC Ref: 20IC6625). All survey respondents consented to the use of their responses for analysis and publication.

Provenance and peer review Not commissioned; externally peer reviewed.

Data availability statement Data are available on reasonable request.

Supplemental material This content has been supplied by the author(s). It has not been vetted by BMJ Publishing Group Limited (BMJ) and may not have been peer-reviewed. Any opinions or recommendations discussed are solely those of the author(s) and are not endorsed by BMJ. BMJ disclaims all liability and responsibility arising from any reliance placed on the content. Where the content includes any translated material, BMJ does not warrant the accuracy and reliability of the translations (including but not limited to local regulations, clinical guidelines, terminology, drug names and drug dosages), and is not responsible for any error and/or omissions arising from translation and adaptation or otherwise.

Open access This is an open access article distributed in accordance with the Creative Commons Attribution Non Commercial (CC BY-NC 4.0) license, which permits others to distribute, remix, adapt, build upon this work non-commercially, and license their derivative works on different terms, provided the original work is properly cited, appropriate credit is given, any changes made indicated, and the use is non-commercial. See: http://creativecommons.org/licenses/by-nc/4.0/.

ORCID iDs

Keir E J Philip http://orcid.org/0000-0001-9614-3580

Nicholas S Hopkinson http://orcid.org/0000-0003-3235-0454

\section{REFERENCES}

1 Pollard CA, Morran MP, Nestor-Kalinoski AL. The COVID-19 pandemic: a global health crisis. Physiol Genomics 2020;52:549-57.

2 Philip K, Cumella A, Farrington-Douglas J, et al. Respiratory patient experience of measures to reduce risk of COVID-19: findings from a descriptive cross-sectional UK wide survey. BMJ Open 2020;10:e040951.

3 Philip KEJ, Lonergan B, Cumella A, et al. COVID-19 related concerns of people with long-term respiratory conditions: a qualitative study. BMC Pulm Med 2020;20:319.

4 Struyf T, Deeks JJ, Dinnes J, et al. Signs and symptoms to determine if a patient presenting in primary care or hospital outpatient settings has COVID-19 disease. Cochrane Database Syst Rev 2020;7:CD013665.

5 Wu Z, McGoogan JM. Characteristics of and Important Lessons From the Coronavirus Disease 2019 (COVID-19) Outbreak in China: Summary of a Report of 72314 Cases From the Chinese Center for Disease Control and Prevention. JAMA 2020;323:1239-42.

6 Hopkinson NS, Rossi N, El-Sayed Moustafa J, et al. Current smoking and COVID-19 risk: results from a population symptom APP in over 2.4 million people. Thorax 2021;76:714-22.

7 Menni C, Valdes AM, Freidin MB, et al. Real-time tracking of self-reported symptoms to predict potential COVID-19. Nat Med 2020;26:1037-40.
8 Hopkinson NS, Jenkins G, Hart N. COVID-19 and what comes after? Thorax 2021;76:324-5.

9 Hall J, Myall K, Lam JL, et al. Identifying patients at risk of postdischarge complications related to COVID-19 infection. Thorax 2021;76:408-11.

10 Mandal S, Barnett J, Brill SE, et al. 'Long-COVID': a cross-sectional study of persisting symptoms, biomarker and imaging abnormalities following hospitalisation for COVID-19. Thorax 2021;76:396-8.

11 Arnold DT, Hamilton FW, Milne A, et al. Patient outcomes after hospitalisation with COVID-19 and implications for follow-up: results from a prospective UK cohort. Thorax 2021;76:399-401.

12 Shah AS, Wong AW, Hague CJ, et al. A prospective study of 12week respiratory outcomes in COVID-19-related hospitalisations. Thorax 2021:76:402-4

13 Townsend L, Dowds J, O'Brien K, et al. Persistent poor health after COVID-19 is not associated with respiratory complications or initial disease severity. Ann Am Thorac Soc 2021;18:997-1003.

14 Stavem K, Ghanima W, Olsen MK, et al. Persistent symptoms 1.5-6 months after COVID-19 in non-hospitalised subjects: a populationbased cohort study. Thorax 2021;76:405-7.

15 NIHR Themed Review: Living with Covid19 - Second review 2021.

16 Sivan M, Taylor S. Nice guideline on long covid. BMJ 2020;371:m4938.

17 NICE. COVID-19 rapid guideline: managing the long-term effects of COVID-19. NG188, 2020.

18 Greenhalgh T, Knight M, A'Court C, et al. Management of post-acute covid-19 in primary care. BMJ 2020;370:m3026.

19 Braun V, Clarke V. Using thematic analysis in psychology. Qual Res Psychol 2006;3:77-101.

20 Lopez-Leon S, Wegman-Ostrosky T, Perelman C, et al. More than 50 long-term effects of COVID-19: a systematic review and metaanalysis. medRxiv 2021:2021.01.27.21250617.

21 Walker AJ, MacKenna B, Inglesby P, et al. Clinical coding of long COVID in English primary care: a federated analysis of 58 million patient records in situ using OpenSAFELY. Br J Gen Pract 2021:2021.2005.2006.21256755.

22 Goërtz YMJ, Van Herck M, Delbressine JM, et al. Persistent symptoms 3 months after a SARS-CoV-2 infection: the postCOVID-19 syndrome? ERJ Open Res 2020;6:00542-2020-2020.

23 Gorna R, MacDermott N, Rayner C, et al. Long COVID guidelines need to reflect lived experience. Lancet 2021;397:455-7.

24 Ladds E, Rushforth A, Wieringa S, et al. Persistent symptoms after Covid-19: qualitative study of 114 "long Covid" patients and draft quality principles for services. BMC Health Serv Res 2020;20:1144.

25 Rockfield S, Chhabra R, Robertson M, et al. Links between iron and lipids: implications in some major human diseases. Pharmaceuticals 2018;11:113

26 Philip K, Gaduzo S, Rogers J, et al. Patient experience of COPD care: outcomes from the British lung Foundation patient Passport. BMJ Open Respir Res 2019;6:e000478.

27 Perlis RH, Haneuse SJPA, Rubenfeld GD, et al. Reporting clinical studies affected by the COVID-19 pandemic: guidelines for authors. JAMA Netw Open 2021;4:e2036155.

28 Mahase E. Covid-19: What do we know about "long covid"? BMJ 2020;370:m2815.

29 Callard F, Perego E. How and why patients made long Covid. Soc Sci Med 2021;268:113426.

30 Barker-Davies RM, O'Sullivan O, Senaratne KPP, et al. The Stanford Hall consensus statement for post-COVID-19 rehabilitation. Br J Sports Med 2020;54:949-59.

31 Wise J. Long covid: who calls on countries to offer patients more rehabilitation. BMJ 2021;372:n405.

32 Polgar O, Aljishi M, Barker RE, et al. Digital habits of PR service-users: implications for home-based interventions during the COVID-19 pandemic. Chron Respir Dis 2020;17:1479973120936685.

33 Puchner B, Sahanic S, Kirchmair R, et al. Beneficial effects of multidisciplinary rehabilitation in postacute COVID-19: an observational cohort study. Eur J Phys Rehabil Med 2021;57:189-98.

34 Bloom Cl, Drake TM, Docherty AB, et al. Risk of adverse outcomes in patients with underlying respiratory conditions admitted to hospital with COVID-19: a national, multicentre prospective cohort study using the ISARIC who clinical characterisation protocol UK. Lancet Respir Med 2021:9:699-711. 